\section{Commentary: Getting in the groove with salvage extracorporeal membrane oxygenation and left ventricular venting}

Douglas M. Overbey, MD, MPH, ${ }^{\mathrm{a}}$ and Andrew J. Lodge, $\mathrm{MD}^{\mathrm{b}}$

Salna and colleagues ${ }^{1}$ present 2 cases of a relatively unique extracorporeal membrane oxygenation (ECMO) cannulation and flow strategy to facilitate recovery following a catastrophic complication of mitral valve repair. In each case, mitral valve repair was complicated by posterior atrioventricular (AV) groove disruption, then managed with internal patching and valve replacement. Cannulation was then reconfigured using both right atrial drainage and a left ventricle (LV) apical vent to prevent distention. This strategy was used for 3 to 4 days postoperatively to decompress the LV to facilitate hemostasis at the repaired AV groove and allow myocardial rest and recovery following a long clamp time. Flow and drainage were titrated using a partial occlusion clamp on the right atrial inflow to ensure 5- to 10$\mathrm{mm} \mathrm{Hg}$ pulsatility in the pulmonary artery and $>1.5 \mathrm{~L}$ flow through the apex cannula. The goals, in addition to ensuring decompression of the LV for enhanced hemostasis and recovery, were also to ensure adequate flow through the mitral valve to prevent thrombosis of the prosthetic valve and adequate flow through the apical cannula to prevent thrombosis in the absence of immediate postoperative heparin administration. Both patients recovered successfully, highlighting the potential success of creative new salvage

From the a Division of Cardiovascular and Thoracic Surgery, Department of Surgery, Duke University Medical Center, Durham, NC; and ${ }^{\mathrm{b}}$ Division of Cardiovascular and Thoracic Surgery, Department of Surgery, Pediatric and Congenital Heart Center, Durham, NC.

Disclosures: The authors reported no conflicts of interest.

The Journal policy requires editors and reviewers to disclose conflicts of interest and to decline handling or reviewing manuscripts for which they may have a conflict of interest. The editors and reviewers of this article have no conflicts of interest.

Received for publication June 2, 2020; revisions received June 2, 2020; accepted for publication June 6, 2020; available ahead of print June 15, 2020.

Address for reprints: Andrew J. Lodge, MD, Duke University Medical Center, Box 3340, Durham, NC 27710 (E-mail: andrew.lodge@duke.edu).

JTCVS Techniques 2020;3:218-9

2666-2507

Copyright $(2020$ The Authors. Published by Elsevier Inc. on behalf of The American Association for Thoracic Surgery. This is an open access article under the CC BY-NCND license (http://creativecommons.org/licenses/by-nc-nd/4.0/).

https://doi.org/10.1016/j.xjtc.2020.06.002

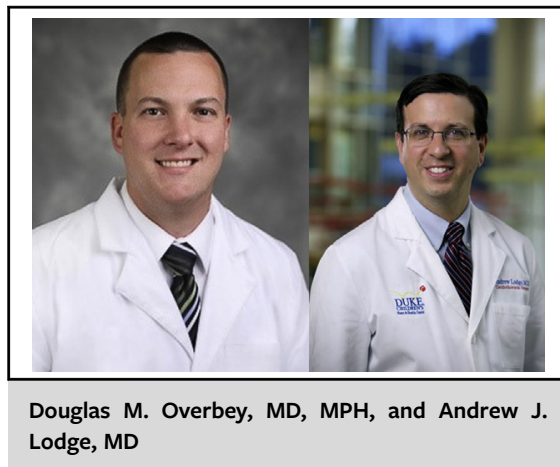

CENTRAL MESSAGE

An extracorporeal membrane oxygenation (ECMO) cannulation and flow maintenancestrategy are proposed to support recovery after posterior atrioventricular groove disruption during mitral valve repair.

therapies involving ECMO for otherwise-devastating complications.

The strength of this report is the salvage of 2 patients from a complication carrying a very high mortality. The authors have capitalized on the expansion of adult ECMO that has involved improved safety and greater levels of comfort taking care of such patients. This novel venting and flow strategy used may allow enhanced hemostasis at the repair site through a decompressed LV without compromising the newly situated mitral valve. This strategy is well explained and should be transferrable to other surgeons and perhaps other complications like ventricular rupture. Although left ventricular decompression is not infrequently needed with conventional veno-arterial ECMO support of cardiac patients due to the increased afterload, ${ }^{2,3}$ this report describes a novel use under dire circumstances. Although postcardiotomy ECMO is associated with high complication rates and low survival, it is often undertaken as salvage when no other options are available. ${ }^{4}$ Limitations of this report include its small size, thus representing proof of concept rather than an analysis of results. The potential impact for this adjunct is that it adds an option where few exist and stimulates further surgical innovation for salvage ECMO techniques.

An important consideration with the salvage strategy described is potential for air entrainment into the circuit. 
The strategy was only used after ongoing bleeding following repair, raising concern over the integrity of the repair. This creates a potential for air entrainment into the circuit through the repair site into the LV vent cannula, particularly in the setting of an open chest. Avoidance of this complication includes meticulous management of flows through each cannula to decompress the ventricle while preventing suction events. This management would include very close continuous observation of the ECMO circuit and dynamic changes of volume status and heart function. Also, and importantly, the authors point out that their approach is an adjunct to conventional surgical therapy and should not be used as a primary treatment for AV groove rupture. The proposed strategy should be reserved for refractory cases of atrioventricular groove rupture but offers an important bailout strategy where other options are sparse.

\section{References}

1. Salna M, Witer L, Argenziano M, Takeda K. Novel adjunctive use of venoarterial extracorporeal membrane oxygenation in atrioventricular groove disruption following mitral valve surgery. J Thorac Cardiovasc Surg Tech. 2020;3:213-5.

2. Tepper S, Masood MF, Baltazar Garcia M, Pisani M, Ewald GA, Lasala JM, et al. Left ventricular unloading by Impella device versus surgical vent during extracorporeal life support. Ann Thorac Surg. 2017;104:861-7.

3. Ok YJ, Jung SH, Lee SW, Ahn JM, Lim JY. Efficacy of left heart decompression during extracorporeal membrane oxygenation: a case-control study. J Thorac Dis. 2019;11:865-72.

4. Khorsandi M, Dougherty S, Sinclair A, Buchan K, MacLennan F, Bouamra O, et al. A 20-year multicentre outcome analysis of salvage mechanical circulatory support for refractory cardiogenic shock after cardiac surgery. J Cardiothorac Surg. 2016;11:151. 